\title{
Optimised Power Error Comparison Strategy for Direct Power Control of the Open-winding Brushless Doubly-Fed Wind Power Generator
}

\author{
Liancheng Zhu, Fengge Zhang, Member, IEEE, Shi Jin, Member, IEEE, Sul Ademi, Member, IEEE, Xiaoying Su, \\ and Wenping Cao, Senior Member, IEEE
}

\begin{abstract}
This paper presents the simulation and experimental evaluation of a novel power error comparison direct power control (PEC-DPC) strategy of the open-winding brushless doubly-fed reluctance generator (OW-BDFRG) for wind energy conversion systems (WECSs). As one of the promising candidates for limited speed range application of pump-alike and wind turbine with partially-rated converter. The emerging OW-BDFRG employed for the proposed PEC-DPC is fed via dual low-cost two-level converters, while the DPC concept is derived from the fundamental dynamic analyses of the calculated and controllable electrical power and flux of the BDFRG with two stators measurable voltage and current. Compared to the traditional two-level and three-level converter systems, the OW-BDFRG requires lower rated capacity of power devices and switching frequency converter, though have more flexible switching mode, higher reliability, redundancy and fault tolerance capability. The performance correctness and effectiveness of the proposed DPC strategy with the selected and optimised switching vector scheme are evaluated and confirmed on a $25 \mathrm{~kW}$ generator test rig.
\end{abstract}

Index Terms-Brushless doubly-fed wind power generators, open-winding, direct power control, dual two-level converters.

\section{INTRODUCTION}

$\mathbf{T}$ HE brushless doubly-fed (reluctance) generators (BDFGs) [1], [2] have some essential features in dealing with issues related to reliability and maintenance operation in long-running variable speed constant frequency (VSCF). Such advantages are due to their robust structure since carbon brushes and slip-rings are eradicated. Moreover they adopt a similar doubly-excited feature similar to doubly-fed induction generators (DFIGs). The BDFGs have evolved from DFIGs but moved the rotor winding to the stator, thus characterised by two standard distributed three-phase stators with different

Manuscript received December 18, 2017; revised April 13 and July 27, 2018; accepted September 12, 2018. This work was supported in part by the National Natural Science Foundation of China under Grant 51537007, and the Natural Science Foundation of Liaoning Province, China, under Grant 201602540 and Youth Foundation of University of Science and Technology Liaoning, China, under Grant 2012QN29. (Corresponding author: Fengge Zhang.)

L. Zhu and X. Su are with the School of Electronic and Information Engineering, University of Science and Technology Liaoning, Anshan, 114051, P. R. China (e-mail: zhuliancheng@163.com; misky88@ sina.com).

F. Zang, S. Jin and X. Su are with the School of Electrical Engineering, Shenyang University of Technology, Shenyang, P. R. China (e-mail: zhangfg@sut.edu.cn; wby-js@163.com; misky88@sina.com).

$\mathrm{S}$. Ademi is with the Warwick Manufacturing Group (WMG), University of Warwick, Coventry CV4 7AL, U.K. (e-mail: s.ademi@warwick.ac.uk).

W. Cao is with the School of Engineering and Applied Science, Aston University, Birmingham B4 7ET, U.K. (e-mail: w.p.cao@aston.ac.uk). applied frequencies and pole pairs [3]. The power winding is grid-connected and control winding (star/delta connection) is fed via two-level converter topology as depicted in Fig. 1.

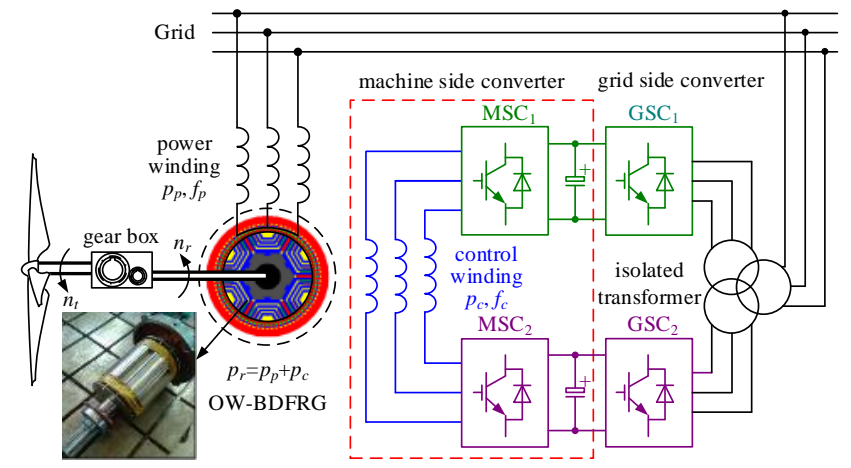

Fig. 1. A conceptual topology diagram of the OW-BDFRG VSCF-WECS for adjustable speed constant frequency grid-connected applications.

The torque production and magnetic field interaction between the two stators are 'modulated' by a specialised rotor with half the total number of the stator poles [4]. As a member of the slip power recovery family, the partially-rated converters of BDFGs are similar to DFIGs. The BDFGs require approximately $30 \%$ of machines rating with a representatively limited speed ratio of 2:1 [5], making them favourable over the fully-rated converter-fed permanent-magnet synchronous generator (PMSG) [6]. Another competitive and important virtue giving recognition to the BDFGs is their low-voltagefault-ride-through (LVFRT) capabilities making them superior to DFIG for grid-connected power generation due to their operating characteristics (no need for extra external crowbar circuitry), their relatively larger leakage inductances and the resulted lower fault current [7]. Advantages of such nature makes the BDFGs a powerful alternative to the widely used DFIGs, especially in medium or large scale off-shore VSCFwind energy conversion systems (WECSs) [1]-[3], [5].

Due to its cage-less structure makes the BDFRG, entail somewhat higher efficiency [8], [9], fewer parameter dependencies, simpler to model and easier to control than brushless doubly-fed induction generator (BDFIG) with a complicated wound (or 'nested' cage) rotor [10]. Furthermore, the relationship between the real and reactive power control in the power winding [11] are inherently decoupled in a similar manner to DFIG [12], [13], but not for the BDFIG counterpart [14]. Thus, the related control strategies proposed for BDFRG are also suitable for the DFIG and vice-versa. 
To date various high performing control strategies have been developed and validated for the prominent and emerging BDFRG. The enriched field of control methods investigated start from vector control (VC) [15], [16], primary-flux (field) oriented control (FOC) with a sensor [11] or without shaftposition [2], sensor [15] or sensorless [17] speed regulation direct torque control (DTC), torque and reactive power control (TQC) [18] and power control (PC) [19]. However, the control strategies mentioned are mostly based on the two-level converters (TLCs), which do not accord best with the large scale WECS in comparison to the three-level converter fed systems in single converter rated capacity and total harmonic distortion (THD) due to its inherent topology [20], [21].

In this paper, a novel three-level converter topology is applied to the open-winding brushless doubly-fed reluctance generator (OW-BDFRG) with hybrid rotor consisting of magnetic barrier reluctance and cage rotor [22]. The control winding is open-circuited and fed by the dual two-level converters (D-TLCs) [23], [24] as shown in Fig. 1. Compared with the traditional TLC and neutral point clamped three-level converter systems (NPC-TLC), the output voltage of D-TLCs can be increased to that of the three-level same as NPC-TLC when the DC-link voltage is equal to D-TLCs. Moreover, the single rated capacity, the voltage of insulated-gate bipolar transistors (IGBTs) power device and the DC-link in the DTLCs can be only half of traditional TLC/NPC-TLC topology.

Furthermore, the redundancy of switching combinations and fault-tolerant control features of the D-TLCs are greatly enhanced. Thus, the cost, performance criterion and robustness are improved which can be applied to the OW-BDFRG to enhance its applicability towards megawatt in VSCF-WECS. Meanwhile, allowing for the control requirement of real and reactive power control for the larger scale VSCF-WECS, the direct power control (DPC) in [1] is adopted and applied to the OW-BDFRG for VSCF-WECS. Consequently, the correctness, effectiveness and validity of the proposed control strategy are confirmed for the BDFRG using traditional star-connection and OW-BDFRG with the proposed optimised DPC strategy based on a $8 / 4$ stator pole. The proposed design methodology is validated through comprehensive simulation and experimental measurements on a $25 \mathrm{~kW}$ BDFRG/OW-BDFRG test rig.

\section{FUndAMENTALS OF BDFRG IN VSCF-WECS}

\section{A. Dynamic Modeling}

In order to enhance the magnetic coupling between the power and control windings, the hybrid rotor structure is designed by superposing the magnetic barrier of reluctance and cage rotor. The reluctance rotor plays the main role in modulating the stator magnetic field, while the cage rotor contributes towards improving the starting performance which is slotted in the non-permeable layer of the magnetic barrier [22]. Thus, according to the equivalent circuit between the two superposed rotor of the BDFRG [8], the space vector model in arbitrary rotating reference frames $\omega$ becomes $\left(d_{p}-q_{p}\right)$ for

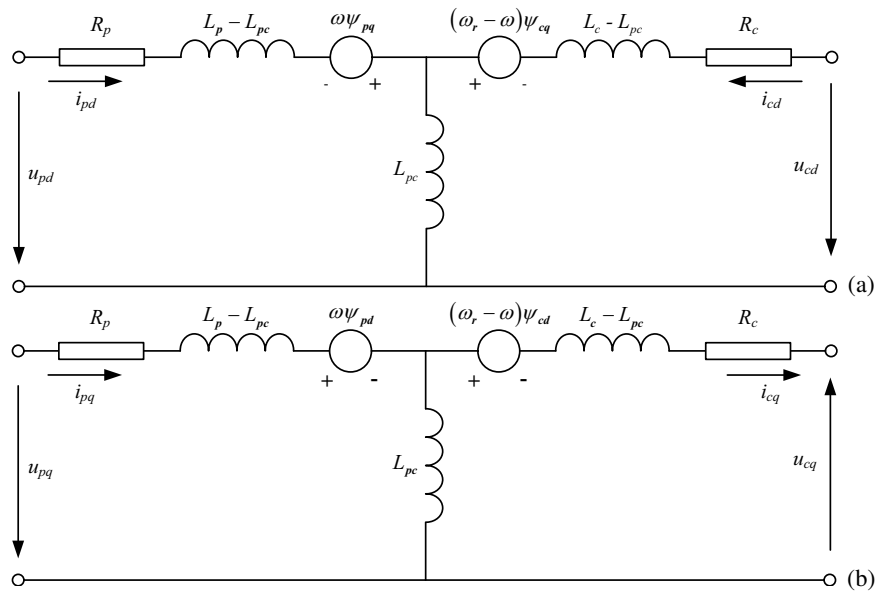

Fig. 2. The BDFRG equivalent circuit. (a) $d$-axis and (b) $q$-axis.

power (primary) winding and $\omega_{r}-\omega\left(d_{c}-q_{c}\right)$ for control (secondary) winding can be described as [4]:

$$
\left\{\begin{array}{c}
u_{p q}=R_{p} i_{p q}+\frac{d\left(L_{p} i_{p q}-L_{p c} i_{c q}\right)}{d t}+\omega \psi_{p d} \\
u_{p d}=R_{p} i_{p d}+\frac{d\left(L_{p} i_{p d}+L_{p c} i_{c d}\right)}{d t}-\omega \psi_{p q} \\
u_{c q}=R_{c} i_{c q}+\frac{d\left(L_{c} i_{c q}-L_{p c} i_{p q}\right)}{d t}+\left(\omega_{r}-\omega\right) \psi_{c d} \\
u_{c d}=R_{c} i_{c d}+\frac{d\left(L_{c} i_{c d}+L_{p c} i_{p d}\right)}{d t}-\left(\omega_{r}-\omega\right) \psi_{c q}
\end{array}\right.
$$

The corresponding $d-q$ axis equivalent circuit are denoted in Fig. 2(a) and (b), while the relationship among the space vectors, $d_{p, c}-q_{p, c}$ components and reference frames are given in Fig. 3 [1], [16].

The subscripts ' $p$ ' and ' $c$ ' denote the corresponding stators, ' $r$ ' represents the rotor components, $L_{p c}$ is the equivalent inductance included in the enhancement for magnetic coupling of the proposed hybrid rotor. The flux linkages are expressed as:

$$
\left\{\begin{array}{l}
\psi_{p q}=L_{p} i_{p q}-L_{p c} i_{c q} \\
\psi_{p d}=L_{p} i_{p d}+L_{p c} i_{c d} \\
\psi_{c q}=L_{c} i_{c q}-L_{p c} i_{p q} \\
\psi_{c d}=L_{c} i_{c d}+L_{p c} i_{p d}
\end{array}\right.
$$

Expression (2) can be expressed as:

$$
\left\{\begin{array}{l}
\boldsymbol{\psi}_{p}=\psi_{p} e^{j \theta_{p}}=L_{p} \boldsymbol{i}_{p}+L_{p c} i_{c}^{*} e^{j \theta_{r}}=L_{p} \boldsymbol{i}_{p}+L_{p c} \boldsymbol{i}_{p c}^{*} \\
\boldsymbol{\psi}_{c}=\psi_{c} e^{j \theta_{c}}=L_{c} \boldsymbol{i}_{c}+L_{p c} \boldsymbol{i}_{p}^{*} e^{j \theta_{r}}=L_{c} \boldsymbol{i}_{c}+L_{p c} \boldsymbol{i}_{c p}^{*}
\end{array}\right.
$$

where $\boldsymbol{i}_{c p}$ and $\boldsymbol{i}_{p c}$ are magnetically coupled (magnetizing) current vectors which come from the actual power/primary $\left(\boldsymbol{i}_{p}\right)$ and control/secondary $\left(\boldsymbol{i}_{c}\right)$ current counterparts rotating at different velocities as shown in Fig. 3. This peculiar frequency modulation through the rotor is hidden in the $e^{j \theta_{r}}$ term in the above equations. Note that $\boldsymbol{i}_{c p}=\boldsymbol{i}_{p}=i_{p} e^{j \epsilon}$ and $\boldsymbol{i}_{p c}=\boldsymbol{i}_{c}=$ $i_{c} e^{j \gamma}$ in Fig. 3 [2], [11].

Note that if $\omega=\omega_{p}, \omega_{r}-\omega=\omega_{c}$, then power and control winding are separated in their respective synchronous rotating reference frame, whereas when $\omega=0, \omega_{r}-\omega=\omega_{r}$ the power winding is in stationary reference frame while control winding is in rotating reference frame, thus such feature makes it feasible for modeling and controlling purposes. 


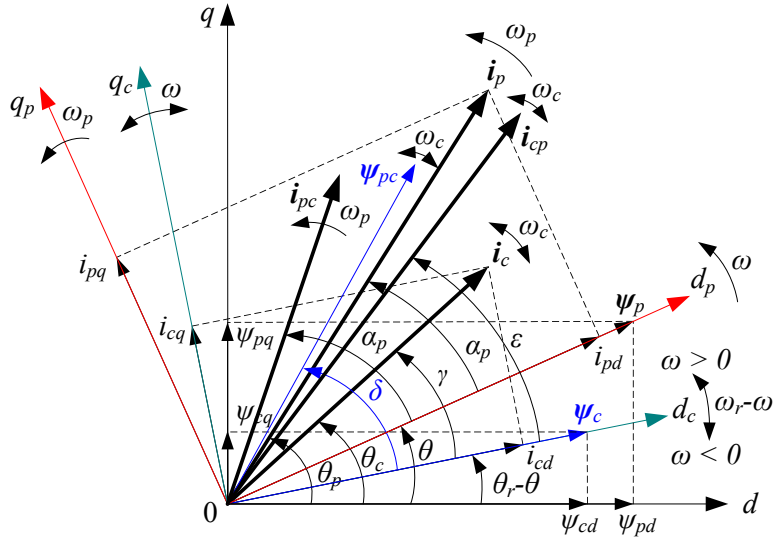

Fig. 3. Space vectors and their corresponding reference frames alignment.

\section{B. Principles of BDFRG for VSCF-WECS}

The magnetic modulation effect with $2 p_{r}$ rotor pole, $f_{p, c}$ frequencies applied to the power and control windings are expressed by equations (4) and (5) (Fig. 1).

$$
\begin{gathered}
f_{p}=\frac{n_{r} p_{r}}{60} \pm f_{c}=\frac{n_{r}\left(p_{p}+p_{c}\right)}{60} \pm f_{c} \\
\omega_{r m}=\frac{\omega_{p}+\omega_{c}}{p_{r}}=\frac{\omega_{p}}{p_{r}}\left(1+\frac{\omega_{c}}{\omega_{p}}\right)=\omega_{s y n}(1-s)
\end{gathered}
$$

where, rotor poles applied with $p_{r}=p_{p}+p_{c}$ to obtain the lower speed for VSCF-WECS; $\omega_{p, c}$ are frequencies $(\mathrm{rad} / \mathrm{s})$ of the power and control windings in Fig. $1 ; s=-\omega_{c} / \omega_{p}$ is defined as the generalized slip; $\omega_{\text {syn }}=\omega_{p} / p_{r}$ represented as the synchronous speed with $\omega_{c}=0$ (or $f_{c}=0$ ), the control winding is fed via DC-link similar to pole pairs $\left(p_{r}\right)$ of wound rotor synchronous turbo-machine. Note that $\omega_{r}>\omega_{s y n}$ for 'super-synchronous' mode, $\omega_{c}>0, s<0$, and the control winding phase sequence is the same as the power winding, thus (4) gets 'negative'; on the other hand, $\omega_{r}<\omega_{\text {syn }}$ for 'sub-synchronous' mode, $\omega_{c}<0, s>0$, the control winding has an opposite phase sequence with the power winding, so (4) gets 'positive'. If one can timely adjust the control winding frequency $\left(f_{c}\right)$ amplitude and its phase sequence when $n_{r}$ changes, then the $f_{p}$ can be kept as the line frequency, which makes the BDFRG suitable for VSCFWECS and hydroelectric generation systems.

\section{BDFRG Applicability/Suitability towards the VSCF-WECS}

According to Betz's theory, the mechanical power captured by the wind turbine under the rated wind velocity can be expressed by equations (6)-(9) [25].

$$
\begin{gathered}
P_{m}=\frac{1}{2} C_{p} \rho \pi R^{2} v_{w}^{3} \\
C_{p}(\lambda, \beta)=0.5176\left(\frac{116}{\lambda_{i}}-0.4 \beta-5\right) e^{-\frac{21}{\lambda_{i}}}+0.0068 \lambda \\
\lambda=\frac{\omega_{t} R}{v_{w}} \\
\frac{1}{\lambda_{i}}=\frac{1}{\lambda+0.08 \beta}-\frac{0.035}{\beta^{3}+1}
\end{gathered}
$$

(a)

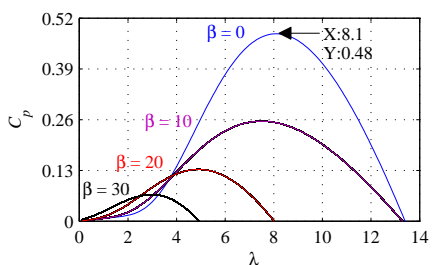

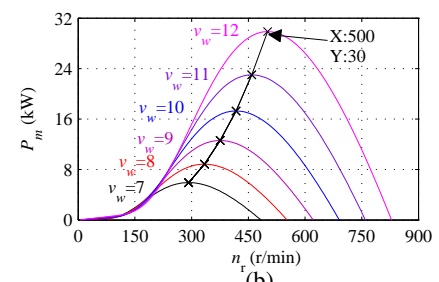

(b)
Fig. 4. Characteristic curves of the wind turbine. (a) $C_{p}-\lambda$ curves with different $\beta$. (b) $P_{m}-n_{r}$ curves and their MPPT with different wind speeds.

The speed relationship between BDFRG and wind turbine can be expressed as:

$$
n_{r}=N n_{t}
$$

where, $P_{m}, C_{p}, R, \lambda, \beta, n_{t}$ and $\omega_{t}$ represent the mechanical power $(\mathrm{kW})$, wind power utilization coefficient, wheel diameter $(\mathrm{m})$, tip speed ratio, pitch angel $\left(^{\circ}\right)$, rotor speed $(\mathrm{r} / \mathrm{min})$ and angular speed $(\mathrm{rad} / \mathrm{s}) ; \rho, v_{w}$ and $N$ denote the air density $\left(\mathrm{kg} / \mathrm{m}^{3}\right)$, wind speed $(\mathrm{m} / \mathrm{s})$ and gear ratio. The turbine parameters are: start-up, rated and range of wind speeds as 3 $\mathrm{m} / \mathrm{s}, 12 \mathrm{~m} / \mathrm{s}$ and $3-25 \mathrm{~m} / \mathrm{s}, R=4.45 \mathrm{~m}, \rho$ is $1.184 \mathrm{~kg} / \mathrm{m}^{3}$, the rated power is $30 \mathrm{~kW}, N=2.234$. The characteristic curves of the wind turbine are shown in Fig. 4, thus $\beta$ should be minimized aiming at capturing the maximum wind energy as represented in Fig. 4(a), $\beta=0$ and $C_{p}=0.48$ when $v_{w}$ is below the rated value. The rotor speed of BDFRG should be adjusted via $f_{c}$ amplitude and its phase sequence according to the oriented values of MPPT as illustrated in Fig. 4(b).

\section{Controller ArRangement with Optimised DPC STRATEGY FOR THE OW-BDFRG}

\section{A. Dual Two-level Converters Topology for OW-BDFRG}

To decrease the rated capacity of a single converter the control winding of the BDFRG is open-circuited and fed by the dual two-level back-to-back converter using a separated DC bus. Such arrangement is deduced via two grid-side converters (GSCs) as shown in Fig. 1, which manifests itself in Fig. 5 also, where the voltage relationships between the control winding and D-TLCs are expressed as:

$$
\left\{\begin{array}{l}
u_{c a}=u_{a_{1} o}-u_{a_{2} o^{\prime}}=u_{a_{1} a_{2}} \\
u_{c b}=u_{b_{1} o}-u_{b_{2} o^{\prime}}=u_{b_{1} b_{2}} \\
u_{c c}=u_{c_{1} o}-u_{c_{2} o^{\prime}}=u_{c_{1} c_{2}}
\end{array}\right.
$$

The voltage space vectors of $\mathrm{MSC}_{1}$ and $\mathrm{MSC}_{2}$ are separately illustrated in Fig. 6(a) and (b). The active vectors are denoted as the vertexes of hexagon with $1-6$ and $1^{\prime}-6^{\prime}$, while zero vectors as centre with $7-8$ and $7^{\prime}-8^{\prime}$. Thus, one can synthesise the voltage space vectors with $\mathrm{MSC}_{1}(1-8)$ and $\mathrm{MSC}_{2}\left(1^{\prime}-8^{\prime}\right)$ for the D-TLCs $11^{\prime}-88^{\prime}$ as demonstrated in Fig. 7 , by adopting the equivalent DC-link voltage $\left(U_{d c} / 2=\right.$

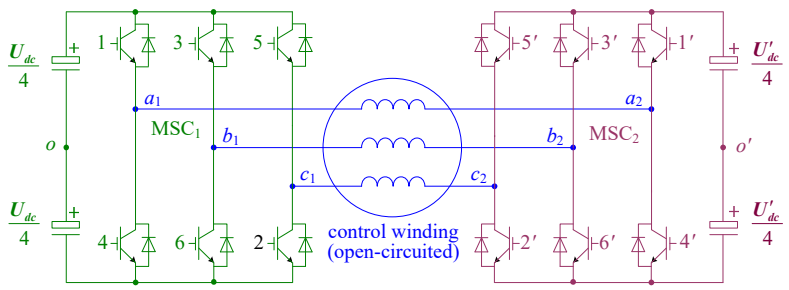

Fig. 5. Topology of D-TLCs with isolated DC bus in OW-BDFRG. 


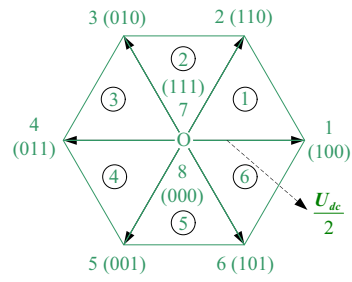

(a)

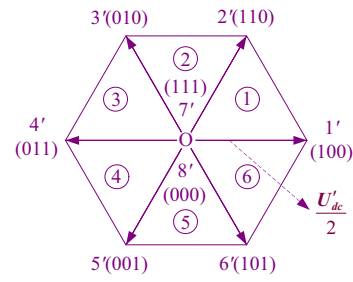

(b)
Fig. 6. Voltage space vector with TLC. (a) $\mathrm{MSC}_{1}$ and (b) $\mathrm{MSC}_{2}$

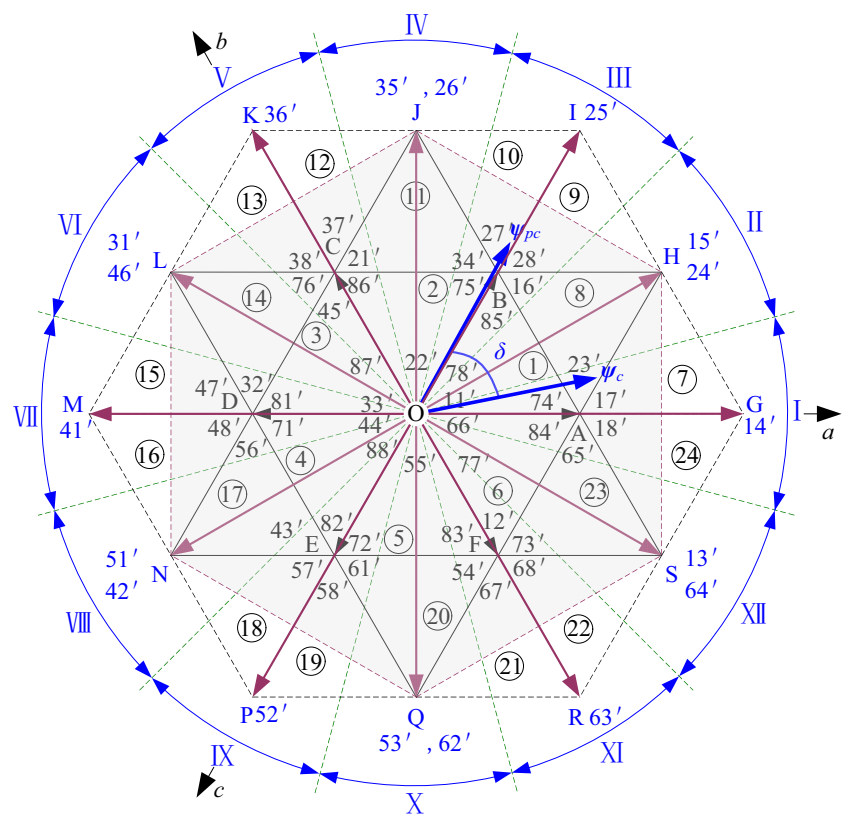

Fig. 7. Combinations of voltage space vector in D-TLCs and the flux position.

$\left.U_{d c}^{\prime} / 2\right)$. Note that the proposed topology adopted in this paper is the isolated DC bus and not the common DC link with full and/or half-controlled converter-fed open-winding PMSG systems requiring common mode current elimination [6], [26].

As shown in Fig. 7, the position and amplitude of the voltage space vectors are similar to the traditional NPC-TLC [20], comprising of 24 smaller sectors and 19 basic voltage vectors: long vectors switching combinations is 6 (OG, OI, $\mathrm{OK}, \mathrm{OM}, \mathrm{OP}$ and $\mathrm{OR})$; middle vectors $(\mathrm{OH}, \mathrm{OJ}, \mathrm{OL}, \mathrm{ON}$, OQ and OS) of D-TLCs is 12 compared to 6 of NPC-TLC; short vectors $(\mathrm{OA}-\mathrm{OF})$ is 36 versus 12 and zero vector is 10 versus 3 of the D-TLCs and NPC-TLC, respectively. Thus, the total switching combinations of D-TLCs is $64\left(2^{3} \times 2^{3}=64\right)$ compared to $27\left(3^{3}=27\right)$ of NPC-TLC. Consequently, the D-TLCs for OW-BDFRG consists of more redundancy and fault-tolerant control features than the NPC-TLC or TLC for BDFRG (star-connection) systems. Furthermore, the DC-link voltage and rated value of D-TLCs are only half of the NPC-TLC (with DC-link voltage $U_{d c}$ ), however, the D-TLCs employs more voltage levels than the TLC system with $U_{d c} / 2$.

\section{B. DPC Mechanisms and Controller Strategy}

The unusual electro-magnetic torque production of OWBDFRG is given as:

$$
T_{e m}=\frac{3 p_{r}}{2 \sigma L_{c}}\left|\boldsymbol{\psi}_{p c} \times \boldsymbol{\psi}_{c}\right|=\frac{3 p_{r}}{2 \sigma L_{c}}\left|\boldsymbol{\psi}_{p c}\right|\left|\boldsymbol{\psi}_{c}\right| \sin \delta
$$

According to the angular velocity expression in (5), the electro-mechanical energy conversion relationship representing the power and control winding contributions can be expressed as:

$$
P_{m}=T_{e m} \omega_{r m}=\underbrace{\frac{T_{e m} \omega_{p}}{p_{r}}}_{P_{p m} \approx P_{p}}+\underbrace{\frac{T_{e m} \omega_{c}}{p_{r}}}_{P_{c m} \approx P_{c}}=\underbrace{P_{p m}}_{\approx P_{p}}(1-s)
$$

where $\delta$ is the torque angle between the mutual magnetic flux $\boldsymbol{\psi}_{p c}$ and $\boldsymbol{\psi}_{c}, \sigma=1-L_{p c}^{2} /\left(L_{p} L_{c}\right)$ is the leakage factor. To grasp the concept of DPC, usually one can ignore the copper losses of the stator windings because of intrinsically lower resistances in larger machines [18], and neglect the changes of magnetic field energy $(d W / d t)$ due to the power winding being directly grid-connected $\left(d W / d t \approx d \psi_{p} / d t \approx 0\right)$. The real power components of stator windings are approximately equal to their mechanical power parts in (13) $\left(P_{p m} \approx P_{p}\right.$, $\left.P_{c m} \approx P_{c}\right)$. Note that in the BDFRG case $\left(T_{e m}<0\right)$ and $P_{c m}$ (also $P_{c}$ ) $<0$ (generating power to the grid) for "supersynchronous' and $P_{c m}\left(P_{c}\right)>0$ (absorbing power from the grid) for 'sub-synchronous' operation. Thus, the four-quadrant reversible back-to-back converter should be employed for bidirectional power flow in the control winding. It is worth mentioning that only $P_{p m}\left(P_{p}\right)<0$ (generating power to the grid) is studied in this paper for MPPT in VSCF-WECS with the wind turbine operating beneath the rated speed.

The proposed controller strategy with optimised power error comparison is shown in Fig. 8. Taking into consideration the control objective and also realise the VSCF-WECS this paper selects the MPPT values as the power winding references $\left(P_{p}^{*}\right)$ in order to capture the maximum wind power available, and in doing so adjusts reactive power reference to zero $\left(Q_{p}^{*}=0\right)$ to achieve unity power factor control (UPFC). One can also set another desired values as $P_{p}^{*}$ and $Q_{p}^{*}$.

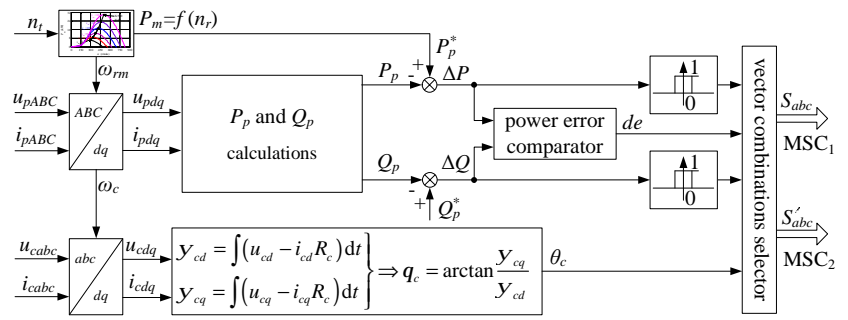

Fig. 8. Controller strategy with the optimised power error comparison-DPC.

According to the instantaneous power theory, the real and reactive power winding can be represented as (14) and Fig. 8 [11].

$$
\left\{\begin{array}{c}
P_{p}=\underbrace{i_{a}}_{i_{p d}} \cdot \underbrace{\frac{u_{a b}+u_{a c}}{2}}_{u_{p d}}+\underbrace{\frac{i_{a}+2 i_{b}}{\sqrt{3}}}_{i_{p q}} \cdot \underbrace{\frac{\sqrt{3} u_{b c}}{2}}_{u_{p q}} \\
Q_{p}=\underbrace{i_{a}}_{i_{p d}} \cdot \underbrace{\frac{\sqrt{3} u_{b c}}{2}}_{u_{p q}}-\underbrace{\frac{i_{a}+2 i_{b}}{\sqrt{3}}}_{i_{p q}} \cdot \underbrace{\frac{u_{a b}+u_{a c}}{2}}_{u_{p d}}
\end{array}\right.
$$

where $u_{p d}, u_{p q}, i_{p d}$ and $i_{p q}$ represent the $d-q$ components of the voltage and current on the power winding, respectively. 
TABLE I

Power Comparators Output and the Hybrid Vector Selection in POWer Error Comparison DPC

\begin{tabular}{|c|c|c|c|c|c|c|c|c|c|c|c|c|c|c|}
\hline \multicolumn{2}{|c|}{ Power Deviation } & Power Error Comparator & \multicolumn{12}{|c|}{ Sector } \\
\hline$P_{p}^{*}-P_{p}$ & $Q_{p}^{*}-Q_{p}$ & $d e$ & I & II & III & IV & $\mathrm{V}$ & VI & VII & VIII & IX & $\mathrm{X}$ & $\mathrm{XI}$ & XII \\
\hline \multirow{4}{*}{1} & \multirow{2}{*}{1} & 1 & $\mathrm{OK}$ & $\mathrm{OL}$ & $\mathrm{OM}$ & $\mathrm{ON}$ & $\mathrm{OP}$ & $\overline{\mathrm{OQ}}$ & OR & OS & $\mathrm{OG}$ & $\mathrm{OH}$ & $\mathrm{OI}$ & OJ \\
\hline & & 0 & OL & $\mathrm{OM}$ & ON & $\mathrm{OP}$ & $\mathrm{OQ}$ & OR & OS & OG & $\mathrm{OH}$ & OI & OJ & $\mathrm{OK}$ \\
\hline & \multirow{2}{*}{0} & 1 & $\mathrm{OI}$ & OJ & $\mathrm{OK}$ & OL & $\mathrm{OM}$ & ON & $\mathrm{OP}$ & OQ & OR & OS & OG & $\mathrm{OH}$ \\
\hline & & 0 & $\mathrm{OH}$ & $\mathrm{OI}$ & OJ & $\mathrm{OK}$ & $\mathrm{OL}$ & $\mathrm{OM}$ & ON & $\mathrm{OP}$ & $\mathrm{OQ}$ & $\mathrm{OR}$ & $\mathrm{OS}$ & $\mathrm{OG}$ \\
\hline \multirow{4}{*}{0} & \multirow{2}{*}{1} & 1 & $\mathrm{OP}$ & $\mathrm{OQ}$ & $\mathrm{OR}$ & $\mathrm{OS}$ & $\mathrm{OG}$ & $\mathrm{OH}$ & OI & OJ & OK & OL & $\mathrm{OM}$ & $\mathrm{ON}$ \\
\hline & & 0 & ON & $\mathrm{OP}$ & $\mathrm{OQ}$ & OR & OS & $\mathrm{OG}$ & $\mathrm{OH}$ & OI & OJ & $\mathrm{OK}$ & OL & $\mathrm{OM}$ \\
\hline & \multirow[b]{2}{*}{0} & 1 & OR & OS & $\mathrm{OG}$ & $\mathrm{OH}$ & OI & OJ & OK & $\mathrm{OL}$ & OM & ON & $\mathrm{OP}$ & $\mathrm{OQ}$ \\
\hline & & 0 & OS & OG & $\mathrm{OH}$ & OI & OJ & OK & $\mathrm{OL}$ & $\mathrm{OM}$ & ON & $\mathrm{OP}$ & $\mathrm{OQ}$ & $\mathrm{OR}$ \\
\hline
\end{tabular}

Then the 3-phase power inputs to the hysteresis comparators are generated from the stationary $d-q$ components (Fig. 3) of the line current and voltage measurements for the primary winding with an isolated neutral point and ' $a b c$ ' phase sequence (Fig. 7). To perceive the PEC-DPC strategy, one can set the real and reactive power error comparator as:

$$
d e=\left\{\begin{array}{l}
1,\left|\Delta P_{p}\right| \geqslant\left|\Delta Q_{p}\right| \\
0,\left|\Delta P_{p}\right|<\left|\Delta Q_{p}\right|
\end{array}\right.
$$

where $\Delta P_{p}=P_{p}^{*}-P_{p}$ and $\Delta Q_{p}=Q_{p}^{*}-Q_{p}$ are the real and reactive power errors. When the $\left|\Delta P_{p}\right|$ fluctuates much more than $\left|\Delta Q_{p}\right|\left(\left|\Delta P_{p}\right| \geqslant\left|\Delta Q_{p}\right|\right)$, then set $d e=1$, which means that the $P_{p}$ should be controlled to track the reference $\left(P_{p}^{*}\right)$ by selecting the proper combination vector; on the contrary, $d e=0$, then the $Q_{p}$ should be controlled to track the reference $\left(Q_{p}^{*}\right)$. The above analysis is illustrated in the next subsection and further emphasised in Tab. I. The quantitative relationship between $\Delta P_{p}$ and $\Delta Q_{p}$ can also be set as other values.

\section{Effects of Voltage Vectors on Power Variations}

Respect to DTC schemes in [17], [27], the mechanisms of the proposed DPC can be analysed and detailed as follows:

1) Allowing for the power winding to be directly gridconnected, $\Psi_{p}$ (amplitude of $\boldsymbol{\psi}_{p},\left|\boldsymbol{\psi}_{p}\right|$ ) and $\Psi_{p c}$ are approximately constant, thus referring to (12) and (13), the $P_{p}\left(P_{p m}\right)$ can be controlled via $\boldsymbol{\psi}_{c}\left(\left|\boldsymbol{\psi}_{c}\right|\right)$ and $\delta$ by selecting the suitable voltage space vectors. The $P_{p}(<0)$ will be increased/decreased meaning less/more power generated towards the grid by decreasing/increasing the $\left(\left|\boldsymbol{\psi}_{c}\right|\right)$ and $\delta$. The voltage space vectors are divided into 12 sectors (I-XII) as depicted in Fig. 7. The short vectors are abandoned because they have the same direction as the long vectors, with only half the amplitude of the long vectors, while the middle vectors have different direction and amplitude with long vectors. To make the best use of the redundancy of D-TLCs topology and obtain the fastest response ratio the middle/long vectors have been adopted as hybrid vectors for the proposed controller strategy. Assuming that the $\psi_{c}$ lies in sector I, where applying the vectors $\mathrm{OH}, \mathrm{OI}, \mathrm{OJ}, \mathrm{OK}$ or OL will decrease $\delta$, thus the OWBDFRG generates less power to the grid $\left(P_{p} \nearrow\right)$, and the vectors $\mathrm{ON}, \mathrm{OP}, \mathrm{OQ}, \mathrm{OR}$ or OS will increase $\delta$ and the OWBDFRG also generate more power to the grid $\left(P_{p} \searrow\right)$.

2) The $Q_{p}$ control logic can be essentially interpreted on the principle of doubly-excited machines since the power and control windings jointly establish the OW-BDFRG magnetic field (flux), if one winding 'contributes' more/less flux, the other will participate less/more during the magnetic excitation. Furthermore, in view of $\Psi_{p}$ (also $\left.i_{p}\right) \sim Q_{p}$, then the $Q_{p}$ $\left(\Psi_{p}\right)$ can be increased/decreased via decreasing/increasing the $\Psi_{c}$ (also the exciting current $i_{c}$ ), which can be implemented by applying the proper voltage space vector(s) with angle between the vector(s) and $\psi_{c}$ less/more than $90^{\circ}$ via the selected switching combinations of D-TLCs. Given that $\boldsymbol{\psi}_{c}$ lies in sector I (Fig. 7), employing vectors OG, OH, OI, OR or OS increases the $\Psi_{c}$ but decrease $Q_{p}(\searrow)$, and the vectors OK, OL, OM, ON or OP decrease $\Psi_{c}$ but increase $Q_{p}(\nearrow)$.

3) Allowing for $\psi_{c}$ in sector I, the OG and OM may cause drastic change to $Q_{p}$, thus abandoned; the $\mathrm{OJ}$ and $\mathrm{OQ}$ will also be discarded due to their small effect in $Q_{p}$. In a similar way, one can deduce that the different influences of any voltage space vectors on $P_{p}$ and $Q_{p}$ when $\psi_{c}$ in any of the sectors.

4) By analysing 1),2) and 3), one can establish that at any instant there will be two voltage vectors which can meet the requirements of $P_{p}$ and $Q_{p}$ control. In addition by applying either $\mathrm{OH}$ or $\mathrm{OI}$ will increase $P_{p}$ and decrease $Q_{p}$ on the basis that $\psi_{c}$ remains in sector I. According to (15), the OI is selected for $\left|\Delta P_{p}\right| \geqslant\left|\Delta Q_{p}\right|$ due to the angle between OI and $\psi_{c}$ which is more than that between $\mathrm{OH}$ and $\boldsymbol{\psi}_{c}$ and $\mathrm{OH}$ for $\left|\Delta P_{p}\right|<\left|\Delta Q_{p}\right|$ because the angle is less (thus more change in $\psi_{c}$, hence $Q_{p}$ ). The latter encompasses the key idea of the proposed controller strategy with PEC-DPC for the OW-BDFRG. The relationship among the vectors with specified switching combinations $P_{p}, Q_{p},\left|\Delta P_{p}\right|$ and $\left|\Delta Q_{p}\right|$ are all illustrated and detailed in Tab. I. Note that the proposed hybrid vector scheme has more redundancy due to its higher switching combinations of the middle vectors.

\section{Simulation Studies}

The performance analysis of the DPC strategy of the BDFRG (star-connection) fed by TLC without 'power error comparator' and the optimised DPC with 'power error comparator' for the OW-BDFRG depicted in Figs. 1 and 8 are modelled in Simulink/SimpowerSystems ${ }^{\circledR}$ library. To make the computer simulations as real as possible, high frequency uncorrelated white noises and unknown slowly varying DC offsets have been superimposed to the ideal signals to account for practical effects of measurements noise, current/voltage transducers and sensor integration errors where the real and reactive power hysteresis errors are $\pm 0.3 \mathrm{~kW}$ and $\pm 0.2 \mathrm{kvar}$, respectively. The machine parameters are given in Tab. II obtained by offline testing, while reference values for BDFRG/OW-BDFRG for VSCF-WECS are shown in Fig. 9. 
TABLE II

THE OW-BDFRG PROTOTYPE PARAMETERS AND RATINGS

\begin{tabular}{|c|c|}
\hline \hline Rated power $\left[P_{N}\right]$ & $25 \mathrm{~kW}$ \\
\hline Power winding resistance $\left[R_{p}\right]$ & $0.3871 \Omega$ \\
\hline Control winding resistance $\left[R_{c}\right]$ & $0.3773 \Omega$ \\
\hline Power winding inductance $\left[L_{p}\right]$ & $40.24 \mathrm{mH}$ \\
\hline Control winding inductance $\left[L_{c}\right]$ & $48.89 \mathrm{mH}$ \\
\hline Mutual inductance $\left[L_{p c}\right]$ & $38.38 \mathrm{mH}$ \\
\hline Stator poles $\left[p_{p} / p_{c}\right]$ & $8 / 4$ \\
\hline Rotor poles $\left[p_{r}\right]$ & 6 \\
\hline Synchronous speed $\left[n_{s y n}\right]$ & $500 \mathrm{r} / \mathrm{min}$ \\
\hline Rated stator voltage $\left[U_{p, c}\right]$ & $380 \mathrm{~V} \mathrm{rms}$ \\
\hline Rated stator frequency $\left[f_{p}\right]$ & $50 \mathrm{~Hz}$ \\
\hline Winding connections & $\mathrm{Y} / \mathrm{OW}$ \\
\hline Rotor inertia $[J]$ & $0.3 \mathrm{~kg} \cdot \mathrm{m}^{2}$ \\
\hline \hline
\end{tabular}

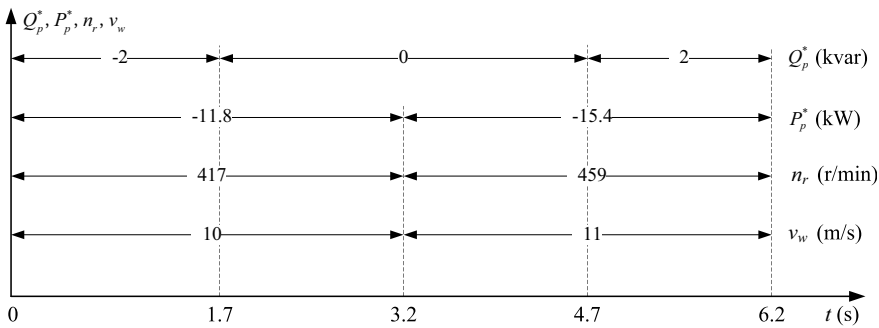

Fig. 9. The executable reference values of DPC strategies for BDFRG/OWBDFRG in VSCF-WECS.

The comparative simulation results of DPC strategy of BDFRG presented in Fig. 10 and the controller strategy with optimised power error comparison (PEC-DPC) adopted for OW-BDFRG depicted in Fig. 11 have been implemented and verified experimentally. The discussion and analysis of the proposed controller strategy with the optimised PEC-DPC for OW-BDFRG in contrast to DPC for the BDFRG will be together executed and illustrated in Section V.

\section{EXPERIMENTAL VERIFICATION}

The experimental test-rig for the proposed controller strategy with the optimised PEC-DPC for OW-BDFRG VSCFWECS is shown in Fig. 12. The prime mover is realized by an inverter-fed induction motor to emulate the wind turbine operation, while the $\mathrm{MSC}_{1,2}$ and $\mathrm{GSC}_{1,2}$ are all based on the traditional two-level back-to-back converter topology with the rated capacity of $15 \mathrm{~kW}$. The current sensor (LT58S7) and the controller core employed was a digital signal controller TMS320F28335. The laboratory measurements have been successfully demonstrated in Figs. 13 and 14, which correspond to the simulation results in Figs. 10 and 11, respecitvely. As shown in Figs. 10-11 and Figs. 13-14(a), (b), the $n_{r}$ rising from $417 \mathrm{r} / \mathrm{min}$ to $459 \mathrm{r} / \mathrm{min}$ (corresponds to the $v_{w} 10 \mathrm{~m} / \mathrm{s}$ to $11 \mathrm{~m} / \mathrm{s}$ ) at $3.2 \mathrm{~s}$, respectively. The $f_{c}$ is $-8.3 \mathrm{~Hz}$ and $-4.1 \mathrm{~Hz}$ for keeping $f_{p}$ as the line frequency of $50 \mathrm{~Hz}$ (VSCF feature of DPC/PEC-DPC for BDFRG/OWBDFRG), where the negative frequency only represents the reversed phase sequence of the control on the power winding expressed in (4). As denoted in Fig. 9, when the $v_{w}$ varies from $10 \mathrm{~m} / \mathrm{s}$ to $11 \mathrm{~m} / \mathrm{s}$, the corresponding real power $\left(P_{p}^{*}\right)$ is $-11.8 \mathrm{~kW}$ and $-15.4 \mathrm{~kW}$ (providing active power to the grid). As evidenced by the results shown in Figs. 11 and 14(c) for the OW-BDFRG a better characteristic performance is shown

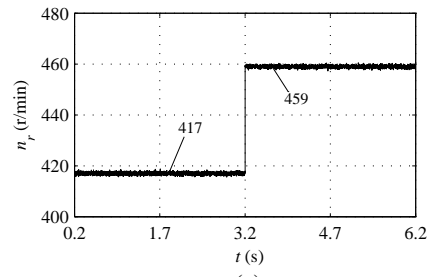

(a)

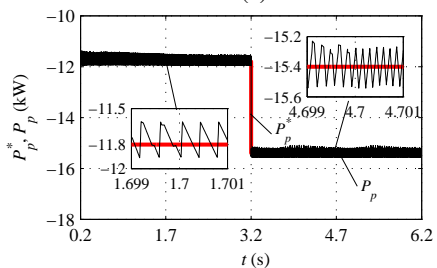

(c)
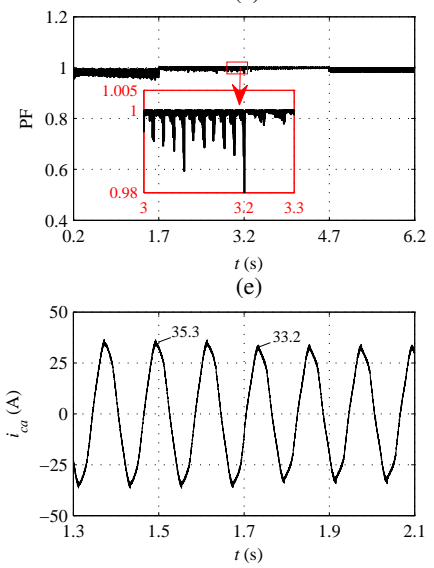

(g)

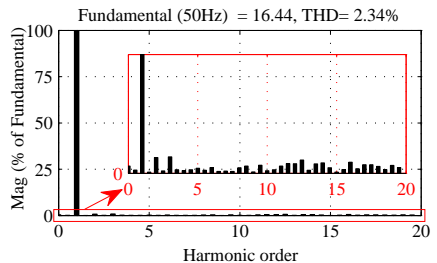

(i)

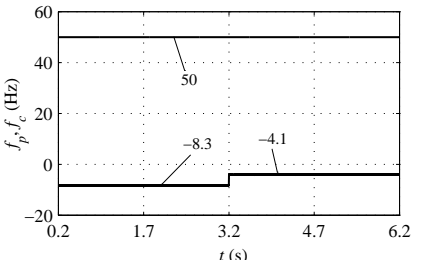

(b)

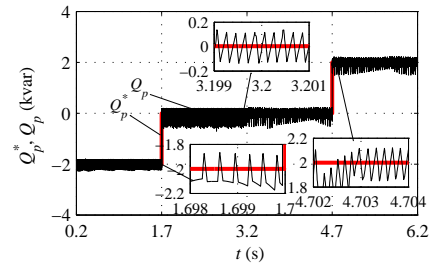

(d)

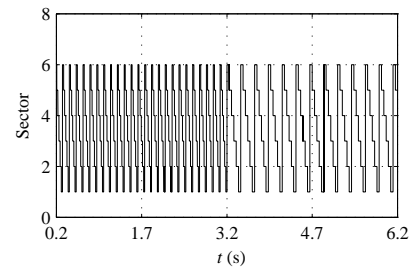

(f)

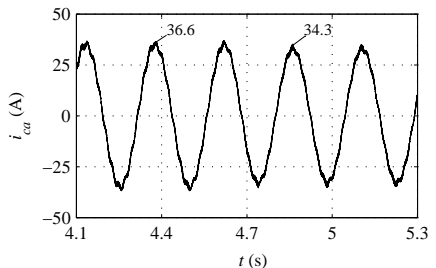

$t(\mathrm{~s})$
$(\mathrm{h})$

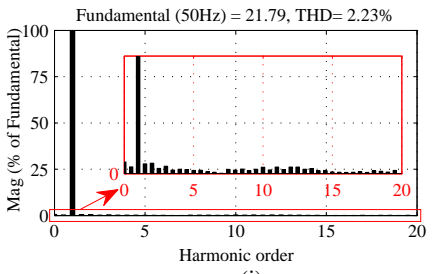

(j)
Fig. 10. Simulation results of DPC with MPPT for BDFRG. a) $n_{r}$, (b) $f_{c}$ and $f_{p}$, (c) $P_{p}^{*}$ and $P_{p}$, (d) $Q_{p}^{*}$ and $Q_{p}$, (e) Power factor in power winding, (f) Sector of $\boldsymbol{\psi}_{c}$, (g) $i_{c a}$, (h) $i_{c a}$, (i) FFT of $i_{p A}$ in $2 \mathrm{~s}-2.04 \mathrm{~s}$, THD $=2.34 \%$ and (j) FFT of $i_{p A}$ in $4 \mathrm{~s}-4.04 \mathrm{~s}$, THD $=2.23 \%$.

by the proposed optimised PEC-DPC in contrast to the results depicted in Figs. 10 and 13(c) for the BDFRG VSCF-WECS.

The power decoupling peculiarities amongst the $P_{p}$ and $Q_{p}$ has been clearly demonstrated, whereby the reactive power $\left(Q_{p}^{*}\right)$ is adjusted accordingly from -2 kvar to 2 kvar at 1.7 $\mathrm{s}$ and $4.7 \mathrm{~s}$ time instants whilst riding through active power at $3.2 \mathrm{~s}$. In addition the unity power factor control is also realised. In addition the excellent aspects (the fluctuation of $Q_{p}$ is much smaller) of the optimised PEC-DPC are verified and shown in Figs. 11 and 14(d), (e) for OW-BDFRG, where better performance is demonstrated in contract to the DPC results depicted in Figs. 10 and 13(d), (e) for BDFRG, especially for the UPFC feature.

In Figs. 10 and 13(f)-(h) the inferred sector location of the secondary flux for the TLC (i.e. 6) and the current curves of control winding $\left(i_{c a}\right)$ are illustrated. On the other hand the inferred sector location for the D-TLCs (i.e. 12) and the control winding current $\left(i_{c a}\right)$ are shown in Figs. 11 and 14(f)-(h). 


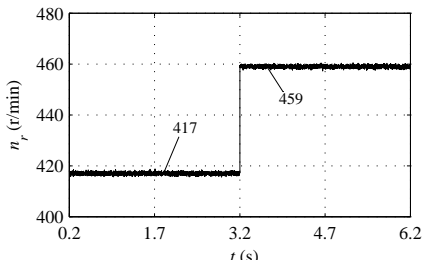

(a)

(c)

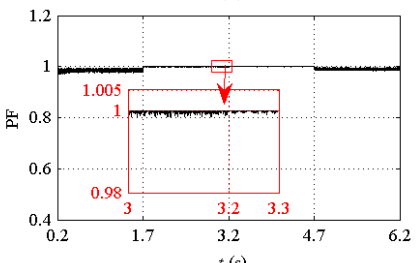

(e)

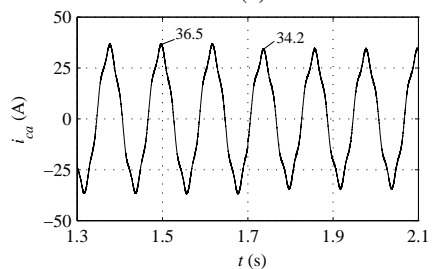

(g)

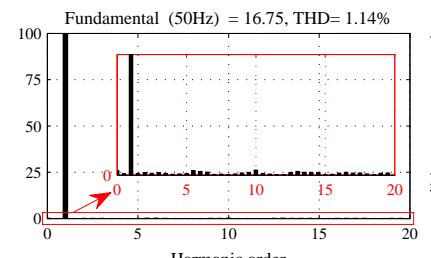

(i)

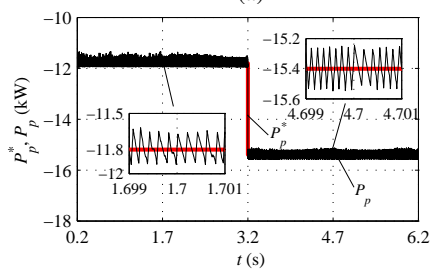

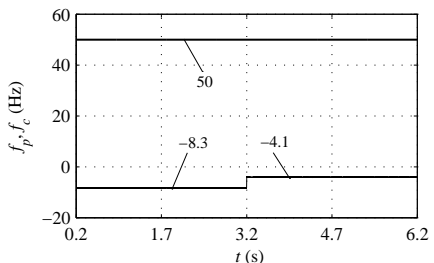

(b)

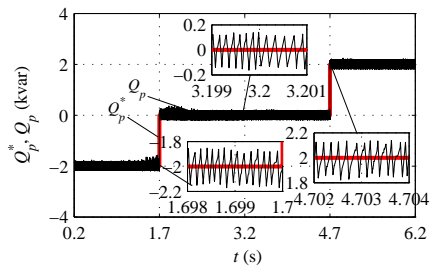

(d)

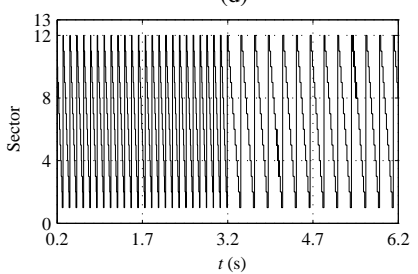

(f)

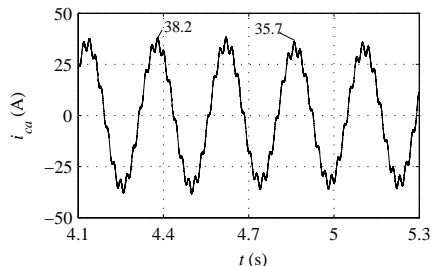

(h)

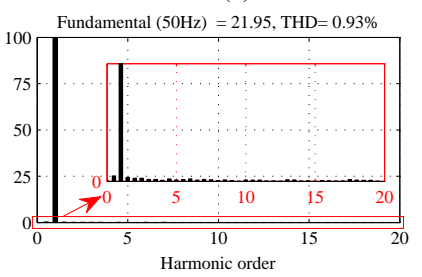

(j)
Fig. 11. Simulation results of the proposed power error comparison-DPC with MPPT using hybrid vectors for OW-BDFRG. (a) $n_{r}$, (b) $f_{c}$ and $f_{p}$, (c) $P_{p}^{*}$ and $P_{p}$, (d) $Q_{p}^{*}$ and $Q_{p}$, (e) Power factor in power winding, (f) Sector of $\boldsymbol{\psi}_{c}$, (g) $i_{c a}$ in $1.3 \mathrm{~s}-2.1 \mathrm{~s}$, (h) $i_{c a}$ in $4.1 \mathrm{~s}-5.3 \mathrm{~s}$, (i) FFT of $i_{p A}$ in $2 \mathrm{~s}-2.04$ $\mathrm{s}, \mathrm{THD}=1.14 \%$ and (j) FFT of $i_{p A}$ in $4 \mathrm{~s}-4.04 \mathrm{~s}$, THD $=0.93 \%$.

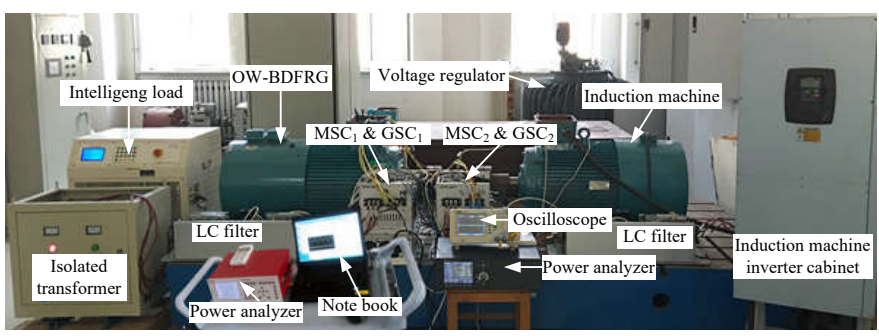

Fig. 12. The OW-BDFRG laboratory test-rig for VSCF-WECS emulation.

The $Q_{p}$ can be controlled by varying the $i_{c a}$ taking into account the feature of doubly-excited machines. $Q_{p}$ can be increased by decreasing the control winding current $i_{c a}$ as shown from the sub-plots presented in (g) and (h), respectively. The fast fourier transform (FFT) analysis corresponding to $i_{p a}$ concerning both controller strategies are evidenced in (i) and (j) as regard to the simulation and experimental results.
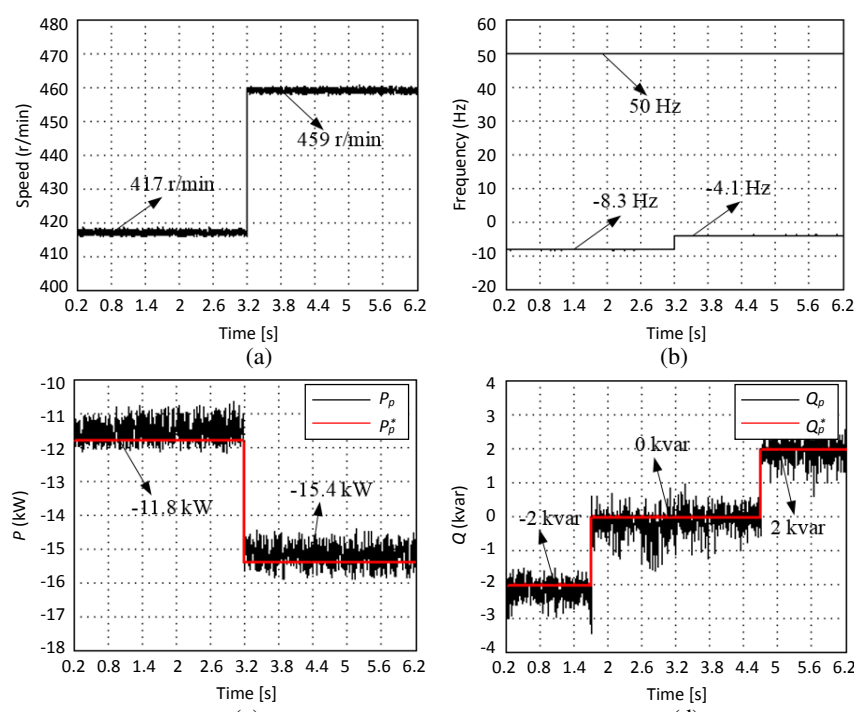

(d)
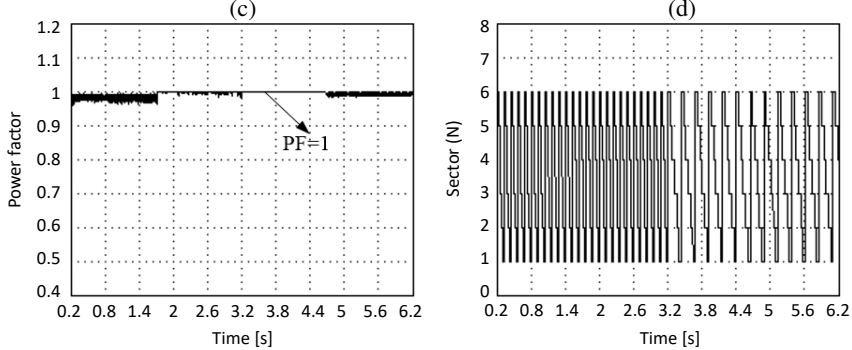

(e)

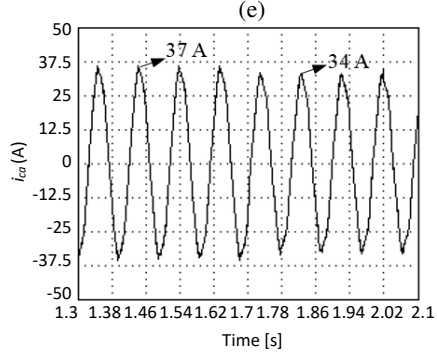

(g)

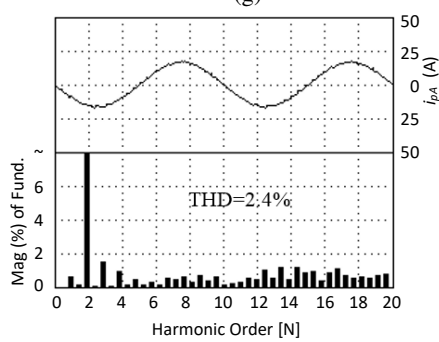

(i)

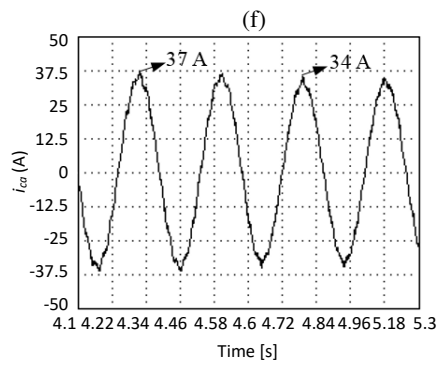

(h)

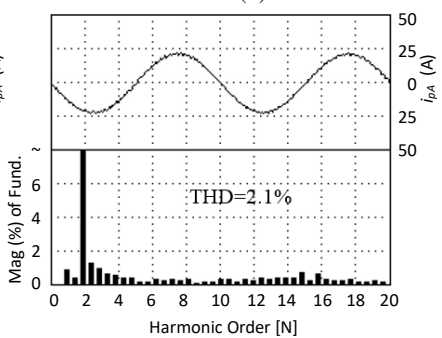

(j)

Fig. 13. Experimental results of DPC for BDFRG. (a) $n_{r}$, (b) $f_{c}$ and $f_{p}$, (c) $P_{p}^{*}$ and $P_{p}$, (d) $Q_{p}^{*}$ and $Q_{p}$ (e) Power factor in power winding, (f) Sector of $\boldsymbol{\psi}_{c},(\mathrm{~g}) i_{c a}$ in $1.2 \mathrm{~s}-2.2 \mathrm{~s}$, (h) $i_{c a}$ in $4.2 \mathrm{~s}-5.2 \mathrm{~s}$, (i) $i_{p A}$ and its FFT in 2 $\mathrm{s}-2.04 \mathrm{~s}, \mathrm{THD}=2.4 \%$ and (j) $i_{p A}$ and its FFT in $4 \mathrm{~s}-4.04 \mathrm{~s}, \mathrm{THD}=2.1 \%$.

The optimised PEC-DPC strategy applied to the OWBDFRG has shown an overwhelming advantage compared to the DPC applied to the BDFRG for VSCF-WECS. The THD of captured waveforms concerning computer simulated results $(1.14 \%$ and $0.93 \%)$ in Fig. 11(i), (j) and (1.8\% and $1.6 \%$ ) concerning the experimental waveforms in Fig. 14(i), (j). The THD analysis for the PEC-DPC for the OW-BDFRG is much smaller in contrast to the results presented for the DPC for the BDFRG as illustrated from the results $(2.34 \%$ and 
2.23\%) in Fig. 10(i), (j) and (2.4\% and 2.1\%) in Fig. 13(i), (j), respectively. Noting that the THD of PEC-DPC for OWBDFRG are decreased by $0.6 \%$ and $0.5 \%$ versus DPC for BDFRG.

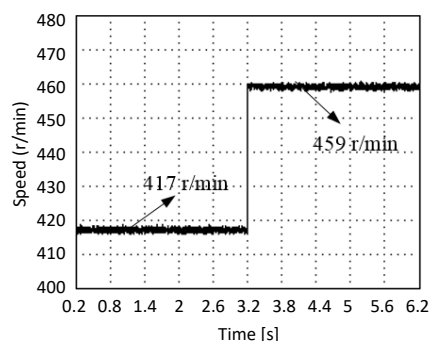

(a)

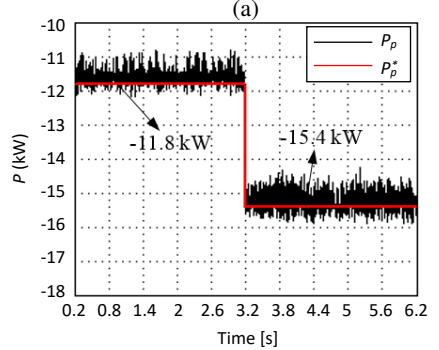

(c)

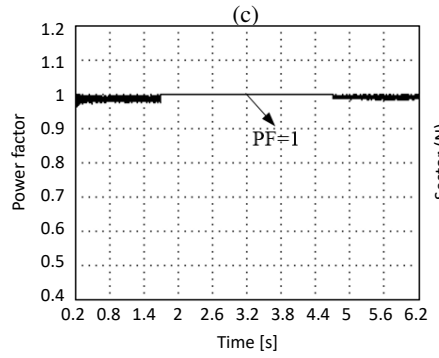

(e)

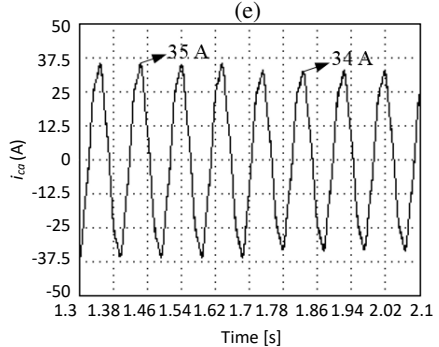

(g)

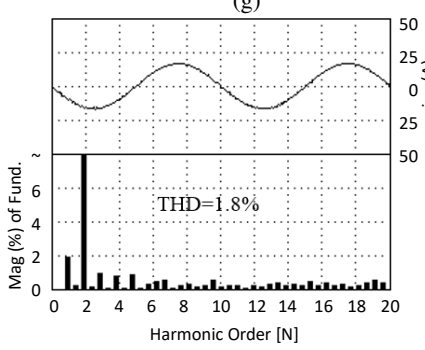

(i)

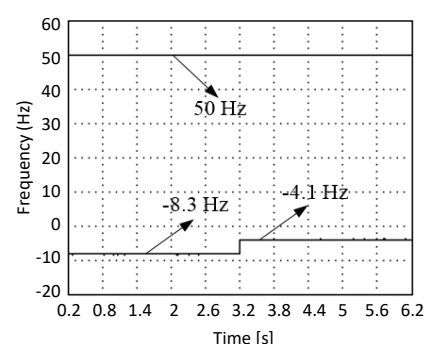

(b)

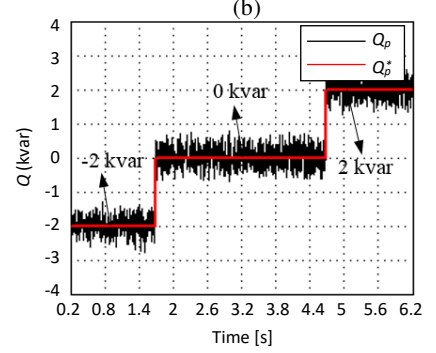

(d)

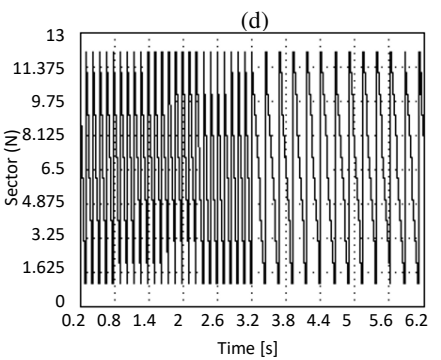

(f)

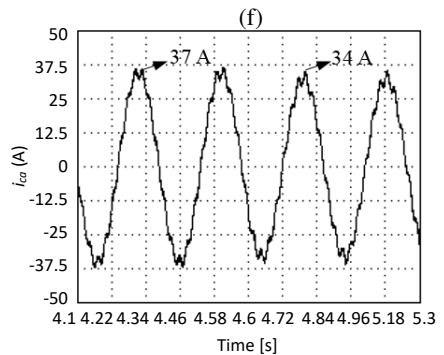

(h)

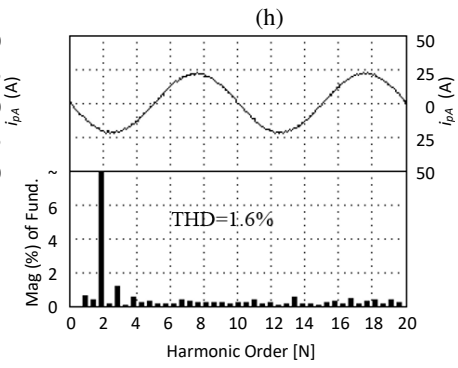

(j)
Fig. 14. Experimental results of PEC-DPC for OW-BDFRG. (a) $n_{r}$, (b) $f_{c}$ and $f_{p}$, (c) $P_{p}^{*}$ and $P_{p}$, (d) $Q_{p}^{*}$ and $Q_{p}$, (e) Power factor in power winding, (f) Sector of $\boldsymbol{\psi}_{c}$, (g) $i_{c a}$ in $1.2 \mathrm{~s}-2.2 \mathrm{~s}$, (h) $i_{c a}$ in $4.2 \mathrm{~s}-5.2 \mathrm{~s}$, (i) $i_{p A}$ and its FFT in $2 \mathrm{~s}-2.04 \mathrm{~s}$, THD $=1.8 \%$ and (j) $i_{p A}$ and its FFT in $4 \mathrm{~s}-4.04 \mathrm{~s}$, $\mathrm{THD}=1.6 \%$.

By comparing the simulation studies and experimental measurements of the proposed PEC-DPC for the OW-BDFRG and the DPC for the BDFRG, various outstanding characteristics of optimised PEC-DPC over DPC have been obtained. The principal advantages include (but not limited to) the better MPPT feature of real $\left(P_{p}\right)$ and reactive power $\left(Q_{p}\right)$ control (also UPFC) with smaller fluctuations in $P_{p}$ and $Q_{p}$; smaller THD characteristic due to its extra voltage levels in the OWBDFRG and the robust speciality even if the $n_{r}$ varies in a wider speed range.

\section{Conclusions}

In this paper, a robust, essentially parameter-free controller strategy with optimised power error comparison DPC for the novel OW-BDFRG fed by the D-TLCs has been proposed. The correctness, effectiveness and feasibility are verified by comparing the detailed simulation results with the experimental measurements of the PEC-DPC and DPC. By contrast with the traditional TLC and NPC-TLC systems, the presented OWBDFRG topology fed via D-TLCs comprises of much smaller rated capacity and DC-link voltage of MSCs and GSCs, which can only be half the nominal ratings of the TLC and NPCTLC (also for IGBTs). Moreover, the output voltage levels are increased from two of TLC to three of NPC-TLC, thus faster response rate for the control system can be obtained. Another very important feature is the overwhelming higher redundancy over the TLC and NPC-TLC. Besides, the THD can be diminished in respect to the TLC, while the switching frequency can be increased or decreased for a similar control.

The presented controller strategy can provide a powerful basis and helpful reference regarding the fault-tolerant control for using the higher redundancy towards the emerging open-winding brushless doubly-fed reluctance generator (OWBDFRG), as a most promising alternative to the DFIG and PMSG currently used for the off-shore generation due to its inherently virtues of brushless robust structure and partiallyrated converter.

\section{REFERENCES}

[1] M. G. Jovanović and H. Chaal, "Wind power applications of doublyfed reluctance generators with parameter-free hysteresis control," Energy Convers. Manage., vol. 134, pp. 399-409, Feb. 2017.

[2] S. Ademi, M. G. Jovanović, H. Chaal and W. Cao, "A new sensorless speed control scheme for doubly fed reluctance generators," IEEE Trans. Energy Convers., vol. 31, no. 6, pp. 993-1001, Sept. 2016.

[3] P. Han, M. Cheng, S. Ademi and M. Jovanovic, "Brushless doubly-fed machines: opportunities and challenges," Chinese Journal of Electrical Eng., vol. 4, no. 2, Jul. 2018.

[4] R. E. Betz and M. G. Jovanovic, "Theoretical analysis of control properties for the brushless doubly fed reluctance machine," IEEE Trans. Energy Convers., vol. 17, pp. 332-339, Sept. 2002.

[5] M. G. Jovanovic, R. E. Betz and J. Yu, "The use of doubly fed reluctance machines for large pumps and wind turbines," IEEE Trans. Ind. Appl., vol. 38, pp. 1508-1516, Nov./Dec. 2002.

[6] Y. Zhou and H. Nian, "Zero sequence current suppression strategy of open winding PMSG system with common DC bus based on zero vector redistribution," IEEE Trans. Ind. Electron., vol. 62, no. 6, pp. 33993408 , Jun. 2015.

[7] S. Tohidi, P. Tavner, R. McMahon, H. Oraee, M. R. Zolghadri, S. Shao and E. Abdi, "Low voltage ride-through of DFIG and brushless DFIG: similarities and differences," Electr. Power Syst. Res., vol. 110, no. 5, pp. 64-72, May 2014.

[8] F. Wang, F. Zhang and L. Xu, "Parameter and performance comparison of doubly-fed brushless machine with cage and reluctance rotors," IEEE Trans. Ind. Appl., vol. 38, no. 5, pp. 1237-1243, Sep./Oct. 2002.

[9] L. Xu, B. Guan, H. Liu, L. Gao and K. Tsai, "Design and control of a high-efficiency Doubly-Fed Brushless machine for wind power generator application," IEEE Energy Conv. Congress and Exposition, Atlanta, GA, pp. 2409-2416, Sep. 2010. 
[10] R. Sadeghi, S. Madani, M. Ataei, A. Kashkooli and S. Ademi, "Supertwisting sliding mode direct power control of brushless doubly-fed induction generator," IEEE Trans. on Ind. Electron., vol. 65, pp. 91479156, Jul. 2018

[11] S. Ademi, M. G. Jovanović and M. Hasan, "Control of brushless doublyfed reluctance generators for wind energy conversion systems," IEEE Trans. Energy Convers., vol. 30, no. 2, pp. 596-604, Jun. 2015.

[12] E. Rezaei, M. Ebrahimi and A. Tabesh, "Control of DFIG wind power generators in unbalanced microgrids based on instantaneous power theory," IEEE Trans. Smart Grid, vol. 8, no. 5, pp. 2278-2286, Sept. 2017.

[13] G. Marques and D. Sousa, "Stator flux active damping methods for fieldoriented doubly fed induction generator," IEEE Trans. Energy Convers., vol. 27, no. 3, pp. 799-806, Sept. 2012.

[14] A. Zhang, X. Wang, W. Jia and Y. Ma, "Indirect stator-quantities control for the brushless doubly fed induction machine," IEEE Trans. Power Electron., vol. 29, no. 3, pp. 1392-1401, Mar. 2014.

[15] M. Jovanović, "Sensored and sensorless speed control methods for brushless doubly fed reluctance motors," IET Electr. Power Appl., vol. 3, no. 6, pp. 503-513, Nov. 2009

[16] S. Ademi and M. G. Jovanović, "Vector control methods for brushless doubly fed reluctance machines," IEEE Trans. Ind. Electron., vol. 62 , pp. 96-104, Jan. 2015.

[17] M. Jovanović, J. Yu and E. Levi, "Encoderless direct torque controller for limited speed range applications of brushless doubly fed reluctance motors," IEEE Trans. Ind. Appl., vol. 42, no. 3, pp. 712-722, May/Jun. 2006.

[18] H. Chaal and M. Jovanović, "Practical implementation of sensorless torque and reactive power control of doubly fed machines," IEEE Trans. Ind. Electron., vol. 59, no. 6, pp. 2645-2653, Jun. 2012.

[19] H. Chaal and M. Jovanovic, "Toward a generic torque and reactive power controller for doubly fed machines," IEEE Trans. Power Electron., vol. 27, no. 1, pp. 113-121, Jan. 2012.

[20] A. Nabae, I. Takahashi and H. Akagi, "A new neutral-point-clamped PWM inverter," IEEE Trans. Ind. Appl., vol. IA-17, no. 5, pp. 518-523, Sept. 1981.

[21] M. Schweizer, T. Friedli and J. W. Kolar, "Comparative evaluation of advanced three-phase three-level inverter/converter topologies against two-level systems, IEEE Trans. Ind. Electron., vol. 60, no. 12, pp. 55155527, Dec. 2013

[22] S. Yu, F. Zhang and H. Wang, "Parameter calculation and analysis of a novel wind power generator, IEEE Trans. Magn., vol. 53, no. 11, pp.1-7, Nov. 2017.

[23] F. Zhang, L. Zhu, S. Jin, W. Cao, D. Wang and J. Kirtley, "Developing a new SVPWM control strategy for open-winding brushless doubly fed reluctance generators," IEEE Trans. Ind. Appl., vol. 51, no. 6, pp. 45674574, Nov./Dec. 2015.

[24] V. T. Somasekhar, S. Srinivas and K. K. Kumar, "Effect of zero-vector placement in a dual-inverter fed open-end winding induction motor drive with alternate sub-hexagonal center PWM switching scheme, IEEE Trans. Power Electron., vol. 23, no. 3, pp. 1584-1591, May 2008.

[25] A. M. Eltamaly, A. I. Alolah and M. Farh, "Maximum power extraction from utility-interfaced wind turbines," New Developments in Renewable Energy, Intech, pp. 159-192, 2013.

[26] H. Nian, Y. Zhou and H. Zeng, "Zero sequence current suppression strategy for open winding PMSG fed by semi-controlled converter," IEEE Trans. Power Electron., vol. 31, no. 1, pp. 711-720, Jan. 2016.

[27] I. Sarasola, J. Poza, M. A. Rodriguez and G. Abad, "Direct torque control design and experimental evaluation for the brushless doubly fed machine," Energy Convers. Manage., vol. 52, no. 2, pp. 1226-1234, Feb. 2011.

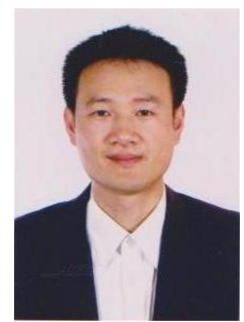

Liancheng Zhu was born in 1979. He received the B.E. and M.S. degree in industry electric automation, control theory and control engineering from the University of Science and Technology Anshan and University of Science and Technology Liaoning, Anshan, China, in 2002 and 2007, respectively, and the Ph.D degree in power electronics and power transmission from the Shenyang University of Technology, Shenyang, China, in 2017.

Since 2002, he has been a Teacher with the School of Electronic and Information Engineering, University of Science and Technology Liaoning. Dr. Zhu has authored or coauthored 34 papers published in important academic journals and presented at domestic and international conferences, of which 24 were cited by SCI/EI. His research interests include power electronics and power transmission, special motors and their control, and wind power generators and their control.

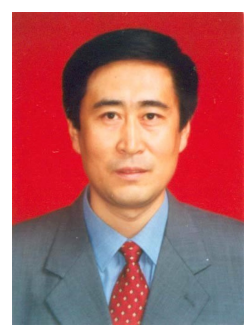

Fengge Zhang (M'17) was born in 1963. He received the B.E., M.S., and Ph.D degrees from the Shenyang University of Technology, Shenyang, China, in 1984, 1990, and 2000, respectively, all in electrical engineering.

Since 1984, he has been a Teacher with the School of Electrical Engineering, Shenyang University of Technology, where he is currently a Professor. From 2001 to 2005, he was a Senior Visiting Scholar and Visiting Professor at Esslingen University of Applied Sciences, Esslingen, Germany. For the last several years, he has been authorized 15 National Invention Patents and published more than 200 papers in important academic journals and international conference proceedings on electrical machines and control systems, of which 120 were cited by SCI/EI.

Prof. Zhang is currently a leader of Electric Machines and Electric Apparats of National Key Disciplines, received nine research awards from the National Machine Industry Ministry, Liaoning Province and Shenyang City, for his outstanding research accomplishments from various research projects completed in recent years. He also received six financial aids from the National Natural Science Foundation of China, Ministry of Education, Liaoning Province, EU international cooperation project and others for his research projects of magnetic field modulation doubly-fed brushless AC machine and high-speed electric machine. His research and teaching interests include special machines and its control technology and new energy power generation.

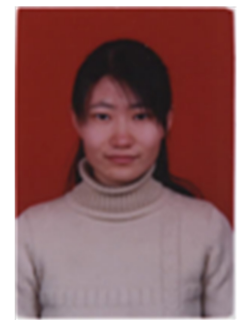

Shi Jin (M'17) was born in 1981. She received the B.E., M.S., and Ph.D degrees from the Shenyang University of Technology, Shenyang, China, in 2004, 2007, and 2011, respectively, all in electrical engineering.

Since 2011, she has been a Teacher with the School of Electrical Engineering, Shenyang University of Technology. Her research and teaching interests include power electronic technology, electrical machines and their control systems, and wind power generation. She has authored or co-authored 41 papers published in important academic journals and presented at domestic and international conferences, of which 32 were cited by SCI/EI.

Dr. Jin has received financial aid from the National Natural Science Foundation of China for her research project Open-Winding Brushless DoublyFed Wind Power Generator With Hybrid Rotor and its Direct Power Control Strategy (Grant 51277124). She was selected as for the Baiqianwan Talents Project of Liaoning Province in 2013.

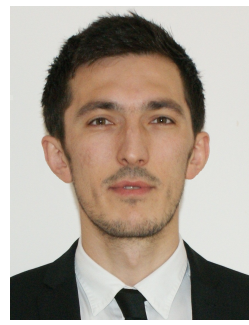

Sul Ademi (M'12) received the B.Eng. and Ph.D. degrees in Electrical and Electronics Engineering from Northumbria University at Newcastle upon Tyne, U.K., in 2011 and 2014, respectively.

From 2015 to 2017, he was a Lead Researcher engaged in knowledge exchange and transfer partnership activities between University of Strathclyde, Glasgow, U.K and GE Grid Solutions, Stafford, U.K., where he focused on the development of novel DC protection schemes suitable for protecting future high-voltage direct current (HVDC) transmission systems. He is currently a Research Scientist with the Warwick Manufacturing Group, University of Warwick, Coventry, U.K.

His main interests are in the areas of electric motor drives, validation of high-performance controllers for variable-speed applications, applications and control of doubly-fed machines, and design and analysis of novel permanentmagnet machines. 


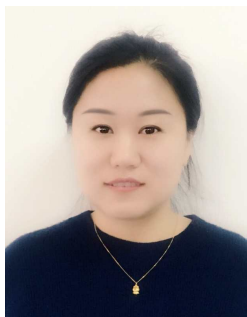

Xiaoying Su was born in 1980. She received the B.S. and M.S. degrees in power system and its automation and systems engineering from the Liaoning Technical University, Fuxin, and the University of Science and Technology, Liaoning, Anshan, China, in 2002 and 2007, respectively. She is currently in her Ph.D degree toward study on direct power control strategy for dual-stator brushless doubly-fed wind power generator from the School of Electrical Engineering, Institute of Electric Control Technology, Shenyang University of Technology, Shenyang,

China.

Since 2002, she has been a Teacher with the School of Electronic and Information Engineering, University of Science and Technology Liaoning. Her research interests include power electronics and power transmission, motors and their control, and wind power generators and their control.

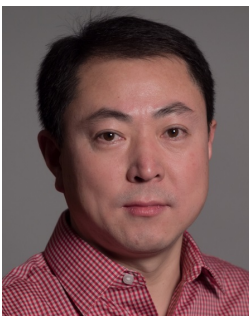

Wenping Cao (M'05-SM'11) received the B.Eng in electrical engineering from Beijing Jiaotong University, Beijing, China, in 1991, and the Ph.D. degree in electrical machines and drives from the University of Nottingham, Nottingham, U.K., in 2004.

$\mathrm{He}$ is currently Chair Professor of Electrical Power Engineering and Head of Power Electronics, Machines and Power System (PEMPS) Group at Aston University, Birmingham, U.K.

Prof. Cao is presently the Chairman for the Industrial Electronics Society, IEEE UK and Ireland Section, and also a "Royal Society Wolfson Research Merit Award" holder, U.K. He was a semi-finalist at the "Annual MIT-CHIEF Business Plan Contest", U.S.A., in 2015; the "Dragon?s Den Competition Award" winner from Queen's University Belfast, U.K., in 2014, the "Innovator of the Year Award" winner from Newcastle University, U.K., in 2013. His research interests include fault analysis and condition monitoring of electrical machines and power electronics. 